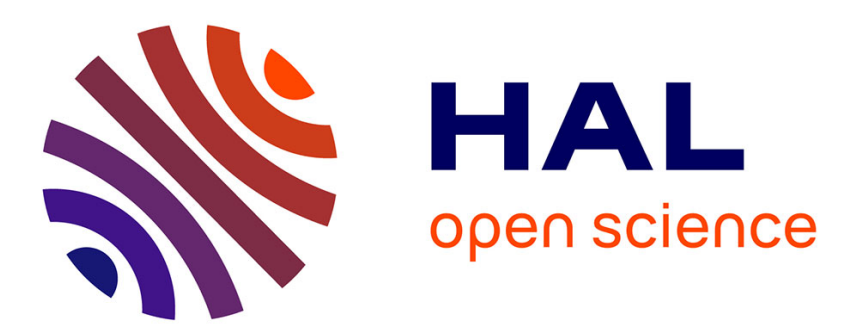

\title{
The Appropriation of Mobile TV through Television Preferences and Communications Networks
}

\author{
Julien Figeac
}

\section{To cite this version:}

Julien Figeac. The Appropriation of Mobile TV through Television Preferences and Communications Networks. Martin C. \& Von Pape T. Images in Mobile Communication. New content, new uses, new perspectives, Springer Verlag, pp.121-141, 2012, 978-3-531-93190-6. 10.1007/978-3-531-93190-6_7 . hal-00943204

\section{HAL Id: hal-00943204 \\ https://hal.science/hal-00943204}

Submitted on 4 Sep 2018

HAL is a multi-disciplinary open access archive for the deposit and dissemination of scientific research documents, whether they are published or not. The documents may come from teaching and research institutions in France or abroad, or from public or private research centers.
L'archive ouverte pluridisciplinaire HAL, est destinée au dépôt et à la diffusion de documents scientifiques de niveau recherche, publiés ou non, émanant des établissements d'enseignement et de recherche français ou étrangers, des laboratoires publics ou privés. 


\title{
The Appropriation of Mobile TV through Television Preferences and Communication Networks
}

\author{
Julien Figeac
}

\section{Introduction}

Six years after the marketing of Mobile television (TV), few French people frequently use multimedia cell phones to watch the fifty-channel broadcast. Some users associate this service with their daily media practices. This choice can be explained by two factors. First, when the television at home is unavailable, teenagers can watch television programs by using mobile phone in their bedrooms. This factor explains the use of this service in residences. Second, many users adopt this service because they use public transportation systems to commute to their workplaces. In addition to listening to music or reading, these users want to be entertained by watching television when travelling. Television viewing is favored over the other forms of media consumption, and the users want to try this new entertainment tool to view their preferred media during their daily commutes.

In this article, we are interested in this second case because users must negotiate two important constraints to watch Mobile TV when commuting. First, their television programming must be adapted to mobile phone screens. For example, can a TV series fan watch the latest episodes by using his telephone? Will the size of the screen, lifespan of the battery and telephone network connection enable him to follow an episode under good conditions? Will these technical constraints encourage him to use Mobile TV less often, choosing shorter programs, such as news shows? Second, the television preferences must be adapted to travel constraints. The user must evaluate whether the duration of an episode corresponds to their trip time. Also, trips between two subway stations and transfers in public transportation are problems for telephone network connections that are linked to underground transport.

Several studies have dealt with these questions. These studies have shown that numerous constraints prevent users from viewing their preferred television programs on mobile phones and while travelling. The small screen size of mobile phones (Chipchase, Yanqing, \& Yung, 2007), the short time slots in which they are used and the noise of urban environments (Södergard, 2003) prompt users to select programs that are not their main television preference. These constraints, linked to Mobile TV, contribute to polarizing this televisual consumption towards the news because these programs can be watched over a short period of time (Knoche \& Mc Carthy, 2005; Oksman, Noppari, Tammela, Mäkinen, \& Ollikainen, 2007). This factor explains why television programs that are not based on a structure of intrigue are at the center of this televisual consumption (Figeac, 2007). These programs have neither a real beginning nor a real ending. They do not tell a story, and a user can watch the shows even if the beginning was missed. The viewer can stop watching the news whenever necessary without being frustrated in not knowing the end. Consequently, users 
tend to favor television content without a structure of intrigue because they can watch them for short moments during their trip. We conclude that the viewers choose their favorite television programs based on a narrative structure that is adapted to the utilization constraints related to daily commuting.

In this report, we describe how users show reflexivity in adopting Mobile TV and adapt their choice of television consumption to mobility constraints. We cannot be satisfied in saying that the viewers use this service to avoid being bored, from a desire to relax or out of simple curiosity or habit without any particular preference (O' Hara, Mitchell, \& Vorbau, 2007). The users show reflexivity in selecting a TV program that can be watched on the small screens of their mobile phone over very short periods while commuting. The users denote a "focus, a suspension, a pause on what is happening" (Hennion, 2004) to select a specific television genre (Corner, 1991) and to evaluate the selected TV program. Through this reflexivity, they evaluate which program is practical to watch in the current circumstances. They evaluate which television preferences are adapted to this new screen and which ones correspond to the mobility constraints. Thus, they review and renew their television preferences based on these evaluations.

Contrary to a structuralist vision of media practices, we will show in this article how users assume control of the renewal of their media practices and how the practical circumstances and the ecological dimension of daily activities intervene in this dynamic of media consumption. We will show how technical mediations also play an active role in the daily renewal of media practices. Indeed, the principal constraint of use encountered when travelling is phone network availability. We will show how users negotiate this constraint as opportunists by transforming it into a resource that enables them to explore new content and new forms of entertainment.

\subsection{The Structuring Effects of an Invisible Technical Mediation}

In this article, we study a specific usage constraint/resource: the availability of a phone network. The connectivity of the network is constraining because it makes the use of Mobile TV possible. The unavailability of the phone network can force users to switch off a program, particularly in underground public transport. This constraint is specific because it refers to "worked urban environments" (Licoppe \& Levallois-Barth, 2009) that access this mobile service usage.

To observe its effects on the appropriation of Mobile TV, we must refer to "ubiquitous computing" (Weiser, 1991) because this work preceded, from a theoretical point of view, the current developments of this service. According to Weiser, technologies must be invisible: they must be embedded in usage environments and must work in the background of the user's awareness. This invisibility of technical mediation can be observed in the use of Mobile TV because the phone network waves are not perceptible to users. The mobile phone manages the connection to this invisible technical network. In addition to this invisibilization of technologies, "ambient intelligence" (Dey, Salber, \& Abowd, 2001) proposes to develop technologies that are able to determine by inference what a user does in a context or tries to do in order to offer the best-adapted service. Mobile services are not (yet) able to produce such opportunities of usage in proposing the relevant service to use in conjunction with the activity of the user, the type of phone network available, the force of the 
signal, the place, the time of day, etc. These adjustments must be made completely by the users. They must evaluate the media supports and the services available during their journey to determine which ones are relevant with regard to the practical circumstances.

This path of research can be explored in the prolongation of ubiquitous computing by observing how users resort to various opportunities of usage offered to them while commuting. The objective is to locate how the invisible work of technologies comes to augment urban environments (Harrison \& Dourish, 1996; Dourish, 2006). The city can be divided into multiple territories, according to their technological equipment and the diversity of usage opportunities it produces. For example, railway stations form territories that are rich in opportunities because they are equipped with multiple communication networks: radio, telephone, GPS and, more recently, Wi-Fi hotspots. It thus becomes interesting to describe how users demarcate places (Harrison \& Dourish, 1996; Dourish, 2006) in urban environments by territorializing their various media activities around the usage opportunities produced by technology. In this article, we will show how users demarcate places to use Mobile TV. Users who choose to watch Mobile TV rather than reading the press will evolve differently in their environments of mobility. The user who replaces reading the press with watching Mobile TV will move differently in urban environments. Indeed, he must evaluate the phone network reception in order to watch a televised program. To do so, the user will decode the graphic indicators of his mobile phone interface. Even if these indicators show the availability of Mobile TV at a precise moment, they do not provide any information on its availability during the trip. This technological resource does not enable the user to coordinate its use with the itinerary effectively, and the user must extract the indications that provide information on the (future) availability of Mobile TV from the urban environment. We will show that the indicators that the user will employ are the same as those that are used to follow the route (i.e., the name of the stations and place names). It is through the indicators that he will identify the places where it will be relevant to watch Mobile TV. Our observation point is thus the availability of the phone network to describe how users proceed to evaluate the connectivity of this technical mediation and, consequently, to evaluate the relevance of Mobile TV use in these practical circumstances. We will show how users demarcate places dedicated to the use of Mobile TV while describing how they index their television reception on the availability of this technical mediation. Through this double appropriation of Mobile TV and its territories of use, we will show how this service comes to supplement or to replace the media activities that the participants developed previously in their trajectory of utilization.

\subsection{Methodology}

The results we will present are extracted from a study in 2007 with a sample of 15 Mobile TV subscribers. This sample is primarily constituted of technophiles; i.e., users 25 to 35 year-old college graduates with a professional occupation in a large French conglomeration (Paris). To observe their uses in situations of mobility, we conducted ethnographic observations by using camera glasses (Relieu, 2002). The users filmed their journeys on public transportation for one week. Our video database is based on the round trips between their residences and their workplaces. It represents approximately 80 hours of recording. 
These video recordings enabled us to describe how travel directs Mobile TV uses and, reciprocally, how the methods of using this service direct the means of travel in urban spaces. To show engagement in this form of multi-activity, we first described the movements of users in public transport: their bust and head movements, their directed regards and their quick glances (Sudnow, 1972). While describing how a user stops looking in the direction of his telephone screen to look at the platform or the name of a station, we will show how his attention is diverted from the activity of following his route to focus on the activity of television reception. Then, while describing how he once again looks at the screen, which was kept within glancing range, we recompose the sequential organization of this form of multi-activity. We show how the distribution of visual engagements between the uses and the itinerary takes the form of a succession of logical operations, prefaced by body positioning.

To describe engagement in this form of multi-activity, we then showed the participants the video recordings of their activities. The objective was to have them explain their intentions and their tactics in using the method of self-confrontation interviews (Theureau, 2004).

This method was developed by ergonomists. It leads the user to discover the parameters, contained in the situational ecology, orienting his practices. Using the recordings, he can clarify his activities as he discovers them. The performativity of self-confrontation interviews constitutes a resource in understanding how media activities and television tastes are positioned. Interviews, questionnaires and logbooks are not very useful in understanding the ecological setting of media activities. The ethnographic observations are also too removed from the activities of the participants to make it possible to observe these settings. With these observations, it is not possible to understand how users articulate their reading of a newspaper and evaluating Mobile TV reception based on information from their mobile phone network indicators. Only the video recordings, coupled with self-confrontation interviews, show the action of these technological and ecological variables in the uses and in the reconfiguration of media activities.

\section{The Reconfiguration of Media Activities as a Function of Communication Network Reception}

The members of our sampling chose to watch Mobile TV while commuting, and they partially reconfigured their old media practices. We see this reconfiguration in examining the case of Linda, a 42-year-old receptionist. The ways in which she uses the media seem paradigmatic because the form of entertainment she chose was reading the newspaper, linked with watching television. To do this, she reorganized her media activities by alternating her reception of various media (press, radio and Mobile TV) according to phone and radio network receptivity. Indeed, during the 80 minutes between her residence and her workplace, she redirected her media activities four times, according to the reception or the unavailability of the telecommunication networks (see figure 8 at the end of this article). We now describe the sequential organization of her media practices. Ever since she has been able to watch television on her mobile phone, Linda does not perform the same ritual before crossing the threshold (Thibaut, 1994) of her residence because she no longer spends her 
The Appropriation of Mobile TV through Television Preferences and Communication Networks

travel time reading. She relies on her new telephone to replace reading magazines with watching Mobile TV.

Even if she no longer takes magazines with her, she still reads while commuting. She now picks up the free daily newspapers that other passengers have left on the seats of the subway. Consequently, in the morning, she enters the underground train searching for a seat where there is a free daily newspaper (see figure 1).

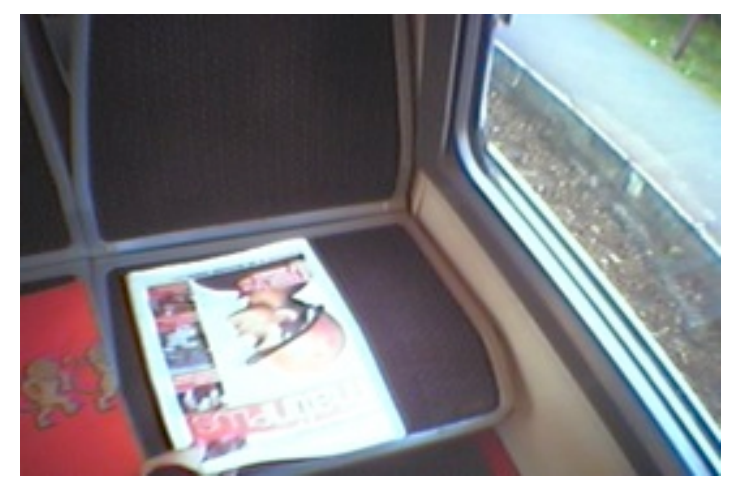

Figure 1: Linda picks up "Matin Plus" before sitting down.

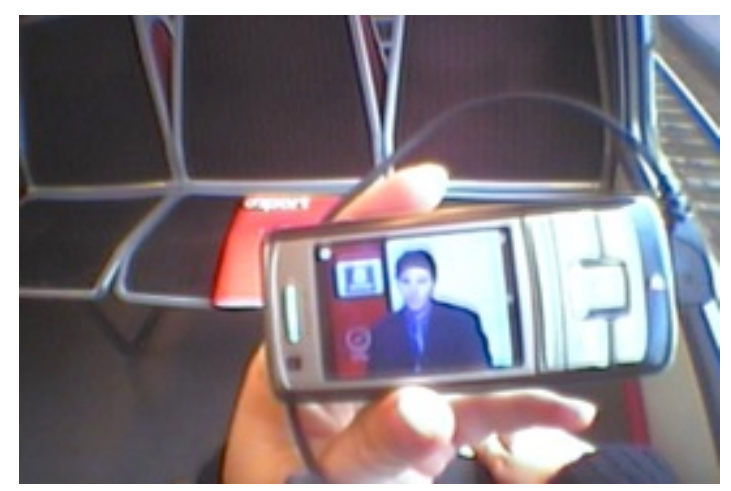

Figure 2: Linda watches "Télématin".

Once she has found a newspaper, she does not read it immediately. She keeps it on her lap in order to read it later (Figure 2). In other words, she carries out a preparatory gesture (Datchary \& Licoppe, 2007): she keeps this media resource and thus shows her intention to use it at another time (during this trip or later at her workplace or at home). It is important to determine when and under what circumstances the reading of the daily newspaper will occur. 
Once seated, she immediately uses her telephone to watch "Télématin" on TV channel France 2 (Figure 2). During the self-confrontation interview, she says that she continues watching television, an activity that she had started during breakfast with her husband and children. Furthermore, she likes to immediately watch Mobile TV because her favorite television program (the TV news show "Télématin") begins at the exact time she takes the subway. In regularly taking this route, she has learned that she will not be able to watch Mobile TV beyond fifteen minutes when the train runs beneath Paris. Consequently, she watches Mobile TV as soon as she sits down in the train because she likes this TV news program, and she knows that it will not be possible for her to use this mobile service afterwards. Figure 8 (at the end of this article) shows how this receptionist watched Mobile TV for 13 minutes between the moment she took the subway $(8: 00$ a.m.) and the moment she no longer had access to the phone network, just after "Télématin". We would like to understand how this user anticipates the unavailability of the phone network to switch off the Mobile TV before using another media. How is this anticipation deployed in regards to the practical circumstances of which it takes advantage?

We will answer this question using the video recordings. We will describe the sequential organization of this transition between these two media activities; i.e., the end of Mobile TV reception and the beginning of reading the daily newspaper. We will show which elements of this usage situation the receptionist perceives as relevant in operating this transition and how this transition is indexed to the availability of the phone network.

\subsection{How the Problems of Reception and Media Activities Form a Pragmatic Test}

To answer these questions, we transcribed the video recording of her trip to work (Figure 8). Once seated in the underground, she watches the televised news while keeping a free daily newspaper on her lap.

The connection to the program lasts approximately 2 minutes 40 seconds between the moment she launched it (01:50:07) and the moment the TV news appears on the screen (04:31:09). Then she watches this program for one minute before losing the connection $(05: 27: 27)$. She needs an additional minute to restore it $(06: 34: 13)$. She watches it again for 4 minutes and 44 seconds before losing the connection with the Mobile TV once again (11:18:17).

This second disconnection occurs 30 seconds after the underground leaves the Bibliothèque François Mitterrand Station (we will call it "BNF") (10:49:74). During the selfconfrontation interview, she specifies: "Here, it cannot be picked up anymore (Mobile TV), so I listen to the radio". This statement proves that she had anticipated the unavailability of Mobile TV because she identified this area as a border area: "after the BNF, nothing can be picked up anymore." When she crosses this borderline on her way to the office, she says she stops using Mobile TV before launching the radio function of her mobile phone that she will listen to while reading a newspaper.

However, the transcription of this journey shows that she tries to connect once again to Mobile TV (11:35:06), even if the subway has left station BNF (10:49:74) for 45 seconds. In other words, she continued to attempt to access Mobile TV after she crossed this borderline. The launching of the connection lasts approximately one minute (12:17:10) until the moment she can watch the televised news again. She succeeds in watching it for seven 
seconds before the program is cut off $(12: 25: 91)$, as she could have predicted. Only after this final attempt does she decides to listen to the radio with the FM tuner of her mobile phone (12:55:20). She activates the radio to listen to it while she reads her free newspaper. She opens the daily newspaper 20 seconds later (13:18:69) when the train arrives at Austerlitz Station (13:26:12) and the Mobile TV reception has become impossible. In these practical circumstances, she consequently reactivates the reading activity that she had left on stand-by 13 minutes before $(00: 25: 08)$ in a preparatory gesture.

With the transcription of this sequence, we understand better why she was hesitant during the self-confrontation interview: "It picks up often, in fact. It picks up until the BNF. From there, after passing the BNF, it does not pick up near Austerlitz. Nothing can be picked up anymore." She knows that a connection with Mobile TV will be difficult at the BNF station, but she is not completely certain. However, she is certain she cannot launch Mobile TV when she is in the following station, Austerlitz. Why is it so difficult for her to identify the exact moment when the phone network is no longer available? Also, why does she continue to try every day to restore connection to this service in an area where the phone network reception is difficult?

We will answer this question by showing that she does not try to optimize these transitions between Mobile TV, the radio and the newspaper, even if she has identified the border where she will be forced to change media activities. The imprecision of this border is not a problem for her. On the contrary, this imprecision enables her to test the technological mediations that connect her to media activities: she continues 1) to handle her telephone to test it, 2) to understand whether the connection problems are related to her telephone or the phone networks, 3) to determine whether the telephone operator has deployed the Mobile TV network in this area, 4) to check if this service is usable in the underground systems in Paris and 5) to reevaluate the borders between Paris (where Mobile TV is unavailable in underground systems) and the suburb where she lives (and where this service can be consulted in overland transport). We now describe how she tests these technological mediations, which frame her media activities, before showing in the last part how this test leads her to requalify the locations of her media practices (de Certeau, 1980; Harrison \& Dourish, 1996; Dourish, 2006).

\subsection{At Time T of Network Indicators}

Users can evaluate the intensity of the phone network with two indicators that are posted on mobile phone screens. The first indicates the type of phone networks to which the telephone is connected (e.g. EDGE, $3 \mathrm{G}, 3 \mathrm{G}+$ ). The second indicates the signal intensity of this phone network. 


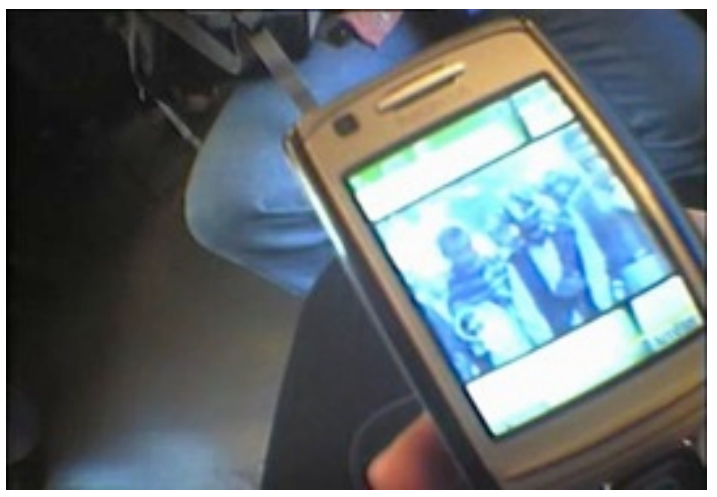

Figure 3: Loss of reception.

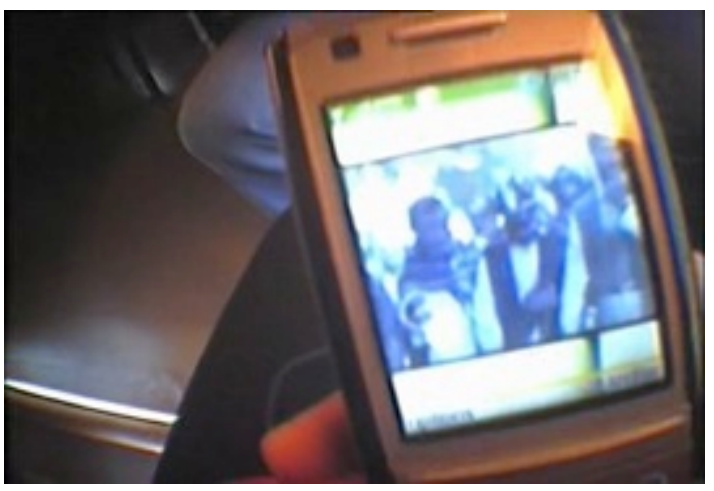

Figure 4: Reception returns.

Using the video recordings, we can observe that Linda is connected to Mobile TV when these indicators show her that this service is available. When she is in an area where she knows from experience that Mobile TV reception is unavailable, she will try to launch this service if these indicators show her that the phone network is (temporarily) available. During the self-confrontation interview, she noted that she had identified that Mobile TV was unavailable between the BNF and the Austerlitz Stations. The phone network indicators, located at the top left of the screen (Figure 3), clearly indicated the loss of the signal to her when the TV news stopped (11:18:17). Just afterwards (11:32:45; Figure 4), these indicators showed her that the network was available again. Consequently, she tried to connect to Mobile TV (11:35:36) even if she knew that this service was usually unavailable at this location. This graphic information made connection to the service relevant under these circumstances.

When the service stopped after this last connection, the indicators showed that the phone networks were unavailable (12:25:91; Figure 5). The indicators contributed to 
dissuading her from using Mobile TV, and encouraged her to read a newspaper and use the radio function on her mobile phone.

These indicators provide support to evaluate under which circumstances she can (or cannot) watch Mobile TV. However, they indicate to users that reception is not possible once the service is blocked, the program is stopped or the image is immobilized. This information appears too late to allow users to anticipate the unavailability of Mobile TV. The limit of these indicators is to reveal instantaneous information, relating the telephone signal reception to a precise moment without specifying the degree of receptivity of the signal in the upcoming minutes. This information would be useful for a user who would like to watch Mobile TV in the subway. An indicator could provide this information to the user if his trip was traced, the orientation of his journey predictable, his stops in the stations anticipated and the speed of his movements were calculated to indicate how long he will be in an area where Mobile TV is available. No technological mediation can fulfill this function (legally).

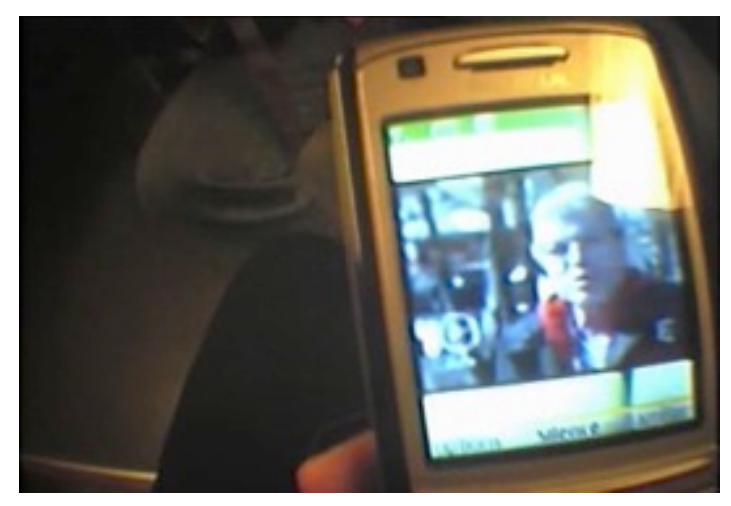

Figure 5: Loss of reception.

Consequently, users must seek other resources to anticipate the telephone signal reception to evaluate whether it is practical to start watching Mobile TV under particular circumstances. To anticipate the connectivity of this invisible technical mediation, environmental indicators that provide information on the telephone signal fluctuations are identified by the users.

\subsection{In Light of an Invisible Technical Mediation}

In addition to the indications given by network indicators, users seek indicators in the surrounding environment to help anticipate the availability of the phone network at moment $\mathrm{T}$ +1 . The users attribute the information given by the telephone interface to their location.

A large amount of information can be used to identify a location. Categorizing all of the architectural elements and other indicators that make it possible for a user to know their location during their daily commute is difficult. It is not possible for us to identify the vari- 
ous indicators by which Linda identifies station BNF. However, she can identify the places where she will be able to watch Mobile TV and to define the borders of where she must use another media by using the indicators. It is possible to isolate one of the parameters that enables her to identify the places of use for Mobile TV. The person who often takes the same route can move while watching Mobile TV. She manages her activities using the perceptible light around the screen of her telephone.

Like all users, Linda thinks that connection to Mobile TV is possible when public transport runs above ground. On the other hand, she thinks that the connection is interrupted when transport moves underground. Consequently, she relies on this indication, formed by light variations, in order to direct her media activities:

J.F.: "And there you are watching TV..."

L.: "Exactly, there the RER is outside, so I start watching TV."

If we take another look at her last connection to Mobile TV in light of this indicator, it appears that she begins this use $(11: 35: 36)$ when the underground has been above ground for more than ten seconds $(11: 23: 22)$. However, when the connection with the TV news program is established $(12: 17: 10)$, the train has just entered a tunnel $(12: 16: 22)$. Consequently, when the reception of this program stopped seven seconds later, this indicator dissuaded her from attempting the connection again because the train had moved underground. This example illustrates how external light is used as an indicator, which is both relevant and problematic, regarding phone network availability.

This example shows how variations in luminosity between the light of day and the semi-obscurity of tunnels can influence the deployment of various uses. When the user is focused on reception, he can easily locate these variations. In this example, Linda does not move her eyes from her telephone screen. She does not need to look outside to find her location because she can identify, through the rays that light the underground train, her departure from the BNF station. She sees in these light variations an indicator showing phone network availability. This supplements information given by network indicators, enabling her to anticipate Mobile TV connectivity at the precise moment $\mathrm{T}+1$; i.e., when the RER train heads above ground.

This example also shows how the information that users extract from external light is problematic. The fact that the RER moved above ground supplemented the information delivered by the network indicators, leading her into error because she could not watch the program for more than seven seconds. For this reason, the participants test the phone network availability every day because no indicator enables them to precisely anticipate these interruptions in connection. Uncertainty involved in the appropriation of Mobile TV shows us that the logic behind utilization proceeds from indications extracted from the situational ecology. However, these indications direct the course of action towards a model that differs from Gibson's theory of perception (Gibson, 1979). For Gibson, the information given by an affordance directs the single activity of a person who is moving. Consequently, the light rays of an affordance overlap a coupling of perception and action without the mediation of reflexivity being necessary; e.g., when a door handle is grasped.

In this case, variations in luminosity in the underground train direct two activities at the same time. The participants make use of these variations to exploit various uses and choose their itinerary. Luminosity transmits information on the phone network availability 
for the person who intends to manage these two activities simultaneously in an urban environment. This indicator is not useful for a user who is in a stopped train because the information from telephone network indicators is sufficient. The relevance of this indicator comes from this mode of involvement for this form of multi-activity. This indicator gives information to the participants who manage their journey on a peripheral level of attention around the Mobile TV screen on which they are focused. The light gives information to the user who awaits its appearance because he makes use of it as a reference mark that prefaces the orientation of its uses. Consequently, Mobile TV reception is embedded as a form of multi-activity because the indicators used to manage it are also used to manage the journey.

\section{The Appropriation of Mobile TV Creates New Forms of Mobility}

We described the commuting of a participant between her residence and her workplace. Because she has started watching Mobile TV, she does not wait for the underground train in the same station as that where she returns home in the evening. Before using this service, she waited for the underground train on the Boulainvilliers station platform. During this wait, she read a newspaper or a magazine. She let the trains that went in other directions of the underground line pass and took the one that stopped at her destination.

When she started using Mobile TV, she reconsidered her itinerary because the telephone network and the radio network were unavailable in this station. Now she enters the first train that stops at this station, no matter what underground line it serves. Then, she makes an intermediate stop in another station to take another train that stops at her destination. She selected this intermediate stop according to Mobile TV availability. Because the phone network is available in the above ground stations, she chose to change trains at the Champs de Mars station near the Eiffel Tower. This station offers a beautiful view of Paris, and she can take advantage of the panorama while watching her favorite television program (Figure 7).

Consequently, she thought of taking this initiative once she had the opportunity to watch Mobile TV. To use this service, she reconsidered her itinerary by modifying her habits. She reconfigured her trip around her attachment to television programs and phone network availability. This itinerary leads to increased mobility (Licoppe \& Inada, 2006) through the use of new technologies. The journey is no longer calculated according to a purely strategic logic of connecting two destinations as quickly as possible. This search for performance is secondary compared to the pleasure felt watching television because she is entertained during the time spent in transport. This pleasure is why she now reorganizes her commuting time around the requirements that must be met in order to watch Mobile TV. 


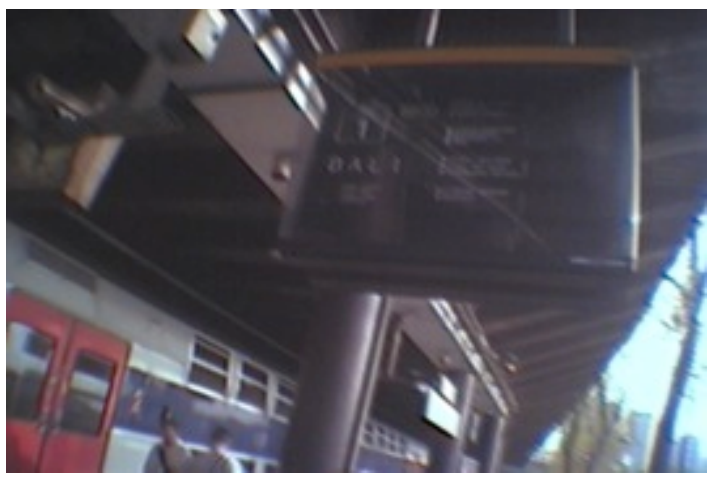

Figure 6: Linda stands near the arrival and departure board.

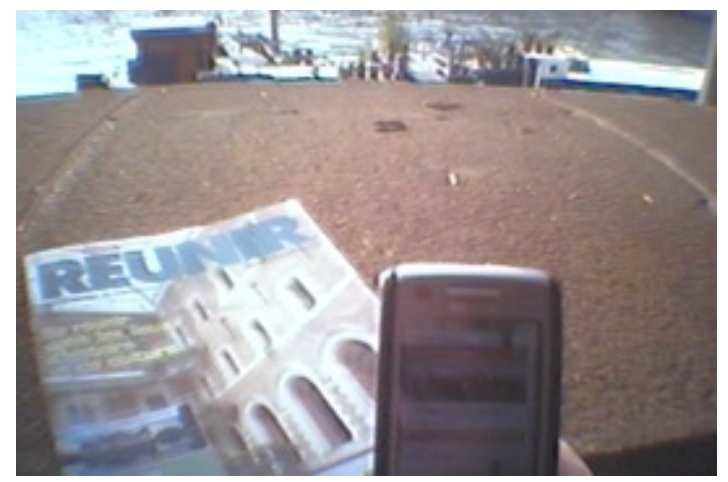

Figure 7: Linda is about to watch Laurent Ruquier's program.

Her engagement in this form of multi-activity made these two communication networks, the phone network and the transport system, converge at this particular place. The place where she stops to watch Mobile TV (Figures 6 and 7) is closely linked to this form of multi-activity. She stands near the arrival and departure board to be able to keep an eye on the arrival of the train (Figure 6). Through her preoccupation with the activity, which she will soon focus on (entering the train), she defines the temporal horizon of the activity of reception in this intermediate place. This example shows how the activities of reception and commuting overlap to form a multi-activity because the control of the first activity interferes with controlling the second and vice versa. As we have seen, the uses of Mobile TV modify the choice of the intermediate stations and the way in which these places are used. It is interesting to see how these places will retroactively affect the uses of this service:

L. : "There I stop at the Champ-de-Mars station. In fact, I could have continued to the BNF station, but I preferred to stop. The weather is nice and all. And what's more, I could 
watch TV. [...] But it is not only because of that. It is also because the station is outside, and the weather is nice. So I can watch TV while soaking up the sun."

J.F.: "And that is why you turned and faced the landscape?"

L.: "Yes, it is. Here, facing the sun, facing the landscape, the Seine river... In spite of the noise of cars and the train...".

She appropriated this place (Harrison \& Dourish, 1996; Dourish, 2006) because it allowed her "to watch TV facing the sun [...], facing the landscape, the Seine river... In spite of the noise of cars and the train...". Consequently, she did not choose this place only because the communication networks were accessible but also for its atmosphere (Thibaud, 1994). She said during the interview that the perception of the sunshine in this place appears to her, retrospectively, as the main reason she left the underground to continue watching TV on the platform: "the weather is nice and all, and what's more, I could watch TV." This example shows that the atmosphere of the places where Mobile TV is used is important in understanding its appropriation. Light is not only an indicator of phone network reception. The bright sunlight illuminates this place (Chelkoff \& Thibaud, 1992). The sunlight makes it prominent on a practical level and makes it conspicuous on a subjective level as a place of exposure, allowing her "to get some sun".

It is necessary to show how technical mediations converge with the atmosphere of the places so that they can be suitable as places to use Mobile TV. If it is relevant to continue the paradigm of increased mobility while describing how the uses of information and communication technologies transform urban mobility, it is also necessary to describe how the emotional tonalities (Thibaud, 1994) of urban environments influence the uses of these technologies. These emotional tonalities do not have a direct impact on the televisual content choices. However, they enter into forming media tastes because they induce pleasures, which bind a user to a media practice and affect his value judgments: to appreciate $\mathrm{Ru}$ quier's television program "facing the sun, facing the landscape, the Seine... In spite of the noise of cars and the train... ".

\section{Conclusion}

Throughout these descriptions, we have shown how the uses of Mobile TV are linked to daily commuting. We have described how a user redefines her itinerary in public transport to watch Laurent Ruquier's program. As an opportunist, she exploits the availability of the phone network in stopping at the stations where Mobile TV reception is possible. She adapts to this constraint in preserving her old media practices to be used during the temporal interstices in which Mobile TV reception is not possible. This technical mediation partially structures her new itinerary by directing her towards certain stations, defining the phases and places (Harrison \& Dourish, 1996; Dourish, 2006) where the uses of the various media become relevant. But these mediations fulfill this function if the user gives them this capacity, i.e., if he exploits them as an opportunist to renew his media activities during his journeys.

The video recordings show how this opportunist attachment with television preferences is carried out like a performance. The problems of Mobile TV reception do not form simple constraints. Even if it is considered to be prejudicial, it pushes the users to refer to their mobile phones and the environments where they wish to use them. It is through this 
referral process and the answers obtained that the appropriation of Mobile TV becomes a performance. As part of the mobile phone network, indicators do not enable them to effectively manage connections to Mobile TV. The users seek indicators that show the availability of the phone network in the urban environments. They exploit the name of the stations and the light variations to delimit and identify the places where Mobile TV reception is reliable. These ecological supports cannot be reduced to simple resources, exploited on a procedural level, in the prolongation of the situated action approach. The performance aspect is because the light of day is perceived differently through a new function. In the same way, the places, the distances between the stations and all this information that can make commuting unpleasant by their recurrence are exploited as invaluable indicators to direct the use of Mobile TV. Multi-activity (Datchary \& Licoppe, 2007) is used to explain this embedding of the indications in the joint control of the uses and the activity of commuting. It is true that our method, based on video recordings, contributes to involving the participant in this state of concern. The user partly records what he sees with camera glasses. He is aware that the researcher can see from the recordings what he was looking at. Consequently, this method incites him to focus his attention on his telephone instead of looking around him and staring at the passengers. This method can amplify the performance engaged in this form of multi-activity. It can encourage users to quickly divide their attention between the media.

Through the concept of multi-activity, we have tried to highlight pragmatic methods of this performance. It seems to be a state of concern (Datchary \& Licoppe, 2007) and a state of continual vigilance. In situations of mobility, the user never isolates himself from the surrounding world. He is vigilant, according to the two meanings of Goffman (1971): 1) to preserve his physical integrity in relation to others and 2) to preserve the normality of his physical appearance. To manage his engagement in this multi-activity, the user remains in a state of awareness to perceive the external signals that can lead him in directing his activity.

Even if the researcher's methodology has a real effect on the practices observed, we can still conclude this study with the following idea: this state of awareness, characteristic of the various forms of multi-activity, shows that the use of Mobile TV must be referenced to the peripheral activities occurring around its use. It is interesting to describe this performance, which consists of carrying out certain activities differently, particularly those that require little attention, such as media activities or cultural attachments. Through the study of Mobile TV uses, we can describe this performance of opportunistic attachment to television programs. This opportunism characterizes a form of attachment in which practical circumstances and technical mediations prompt users to select certain media preferences. This form of attachment is specific because there are not that many people using these services. Today, users have many different media preferences, which are constantly increasing with the growth of media. Consequently, to understand the adoption of new media and complementarities between various media, it is interesting to observe which media preferences they will select according to the utilization opportunities produced by new technologies and new services. 
The Appropriation of Mobile TV through Television Preferences and Communication Networks

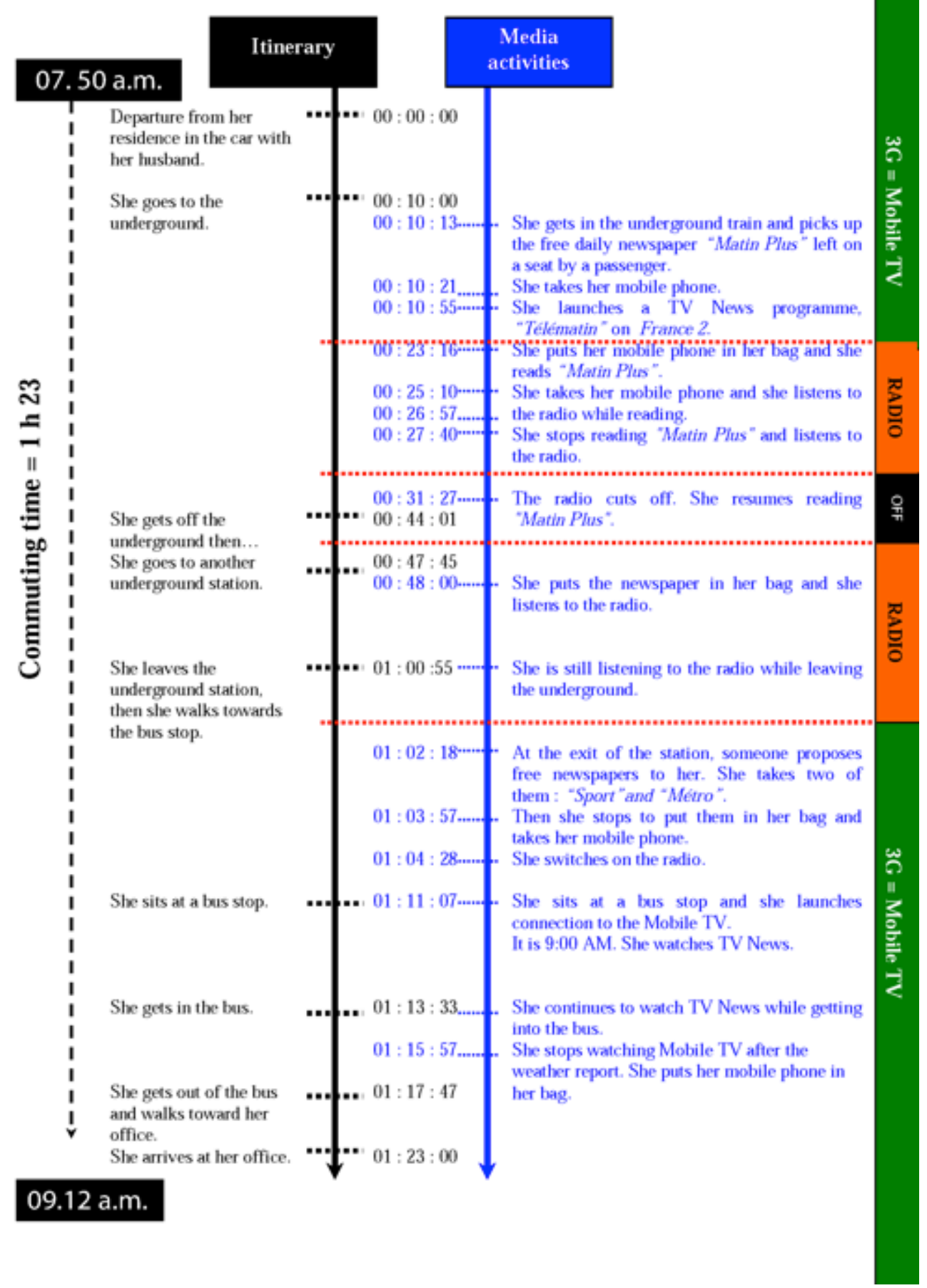

Figure 8: Linda's trip between her residence and her workplace 


\section{References}

de Certeau, M. (1984). The Practice of Everyday Life. Berkeley, CA: University of California Press (Original work published 1980).

Chelkoff, G. \& Thibaud, J. P. (1992). L'espace public, modes sensibles: Le regard sur la ville. Les Annales de la recherche urbaine, 57 \& 58, 7-16.

Chipchase, J., Yanqing, C., \& Jung, Y. (2007). Personal TV: A Qualitative Study of Mobile TV users. Proceedings of the 5th European Conference, EuroITV 2007, Amsterdam, Netherlands.

Corner, J. (1991). Meaning, genre and context: the problematics of "public knowledge" in the audience studies. In J. Curran and M. Gurevitch (Eds.), Mass media and society. London: Edward Arnold.

Datchary, C. \& Licoppe, C. (2007). La multi-activité et ses appuis: L'exemple de la "présence obstinée" des messages dans l'environnement de travail. @ctivités, 4(1), 4-29.

Dey, A. K., Salber, D., \& Abowd, G. D. (2001). A conceptual framework and a toolkit for supporting the rapid prototyping of context-aware applications. Human-Computer Interaction (HCI) Journal, 16(2-4), 97-166.

Dourish, P. (2006). Re-Space-ing Place: "Place" and "Space" Ten Years On. Proceedings of the 20th anniversary conference on Computer supported cooperative work CSCW'06. Banff, Alberta, Canada.

Figeac, J. (2007). La configuration des pratiques d'information selon la logique des situations. Réseaux, 25(143), 17-44.

Gibson, J. J. (1979). The ecological approach to visual perception. Boston: Houghton-Mifflin.

Goffman, E. (1971). Relations in Public: Micro-Studies of the Public Order. New York: Basic Books.

Harisson, S. \& Dourish, P. (1996). Re-Place-ing Space: The Roles of Space and Place in Collaborative System, Proceedings of the 20th anniversary conference on Computer supported cooperative work CSCW'06. Banff, Alberta, Canada.

Hennion, A. (2004). Pragmatics of taste. In M. Jacobs and N. Hanrahan (Ed.), The Blackwell Companion to the Sociology of Culture (pp. 131-144). Oxford, Malden: Blackwell.

Knoche, H. \& McCarthy, J. D. (2005). Good News for Mobile TV. Proceedings of Wireless World Research Forum 14. San Diego, CA, USA.

Licoppe, C. \& Inada, Y. (2006). Emergent Uses of a Location-aware Multiplayer Game: The Interactional Consequences of Mediated Encounters. Mobilities, 1(1), 39-61.

Licoppe, C. \& Levallois-Barth, C. (2009). Configurer l'accessibilité des voyageurs équipés à des services mobiles multimédia: Le cas des publicités "augmentées" par Bluetooth dans le métro parisien. Réseaux, 4(156), 15-48.

O'Hara, K., Mitchell, A. S., \& Vorbau, A. (2007). Consuming Video on Mobile Devices. Proceedings of the SIGCHI conference on Human factors in computing systems. San Jose, California, USA.

Oksman, V., Noppari, E., Tammela, A., Mäkinen, M, \& Ollikainen, V. (2007). News in Mobiles: Comparing text, audio and video. VTT Research Notes 2375. Available: http://www.vtt.fi/inf/pdf/tiedotteet/2007/T2375.pdf [May 31, 2011].

Relieu, M. (2002). The "glasscam" as an observational tool for studying screen-based mobile phone uses and management of parallel activities. Proceedings of the International Conference on Conversation Analysis (ICCA-02). Copenhagen, Denmark.

Södergard, C. (2003). Mobile television: Technology and user experiences. Report on the Mobile-TV project, VTT Information Technology.

Sudnow, D. (1972). Temporal parameters of interpersonal Observation. In D. Sudnow (Ed.), Studies in social interaction (pp. 259-279). New York: The Free Press.

Theureau, J. (2004). Le cours d'action: Analyse sémio-logique. Un essai d'une anthropologie cognitive située. Toulouse: Octarès. 
The Appropriation of Mobile TV through Television Preferences and Communication Networks

Thibaud, J.-P. (1994). Les mobilisations de l'auditeur-baladeur: une sociabilité publicative. Réseaux, 12(65),71-83.

Weiser, M. (1991). The Computer for the Twenty-First Century, Scientific American, 265(3.), 94-104. 